\title{
Bainite-like Transformation in Zirconia Ceramics
}

\author{
Norihiko Nakanishi* and Toshihiko Shigematsu*
}

\begin{abstract}
The authors have found in $\mathrm{ZrO}_{2}-\mathrm{Y}_{2} \mathrm{O}_{3}$ ceramics, an isothermal propagation of martensitic transformation, tetragonal to monoclinic, which occurred by means of a similar mechanism to generate the lower bainite in steels. This isothermal propagation of monoclinic phase appears to be controlled by the oxygen-ion diffusion or the interaction between so-called Frenkel type defects and oxygen ions which existed in the tetragonal lattice (a distorted $\mathrm{CaF}_{2}$ structure) of $\mathrm{ZrO}_{2}$ containing a few mol percents of $\mathrm{Y}_{2} \mathrm{O}_{3}$. Accordingly, the behaviour of nucleation and growth (propagation) of monoclinic martensite can be described in the same way as the homogeneous nucleation theory which often appeared in precipitation phenomena. On the other hand, the typical athermal behaviour of tetragonal to monoclinic transformation was observed in $\mathrm{ZrO}_{2}-12 \mathrm{~mol} \% \mathrm{CeO}_{2}$ ceramics, in which the "Bainite-like" mechanism cannot be expected because of the existence of only a small amount of thermodynamical oxygen vacancies in the tetragonal lattice. However, in 8 $\mathrm{mol} \% \mathrm{CeO}_{2}$ specimens the isothermal propagation has been reported by Shimada et al., suggesting that the transformation behaviour must be very much affected by the $\mathrm{CeO}_{2}$ content. A brief discussion was focussed to the origin of different mechanisms observed in $\mathrm{ZrO}_{2}$-base ceramics.
\end{abstract}

(Received March 25, 1991)

Keywords: bainite-like transformation, martensitic transformation, isothermal propagation, athermal martensite, diffusion, nucleation and growth, Frenkel type defect, $\mathrm{ZrO}_{2}-\mathrm{Y}_{2} \mathrm{O}_{3}$ ceramics, $\mathrm{ZrO}_{2}-\mathrm{CeO}_{2}$ ceramics

\section{Introduction}

Meaning of "Bainite-like" transformation: According to Nishiyama ${ }^{(1)}$, so-called lower-bainite is made by a diffusionless transformation from austenite $(\gamma)$ to ferrite $(\alpha)$ in steels where the transformation requires not only a shear mechanism but also an individual atomic movement, and accompanies small non-chemical energies; lattice invariant deformation and interface energies associated with the transformation. Therefore, if temperature is lower than $T_{0}$ (the equilibrium temperature between $\gamma$ and $\alpha$ phases), the lower-bainitic transformation can occur even at temperatures higher than the $M_{\mathrm{s}}$ temperature. Although the progress of this transformation is usually prevented by volume strains caused by an expansion of martensitic transformation, the growth of the bainitic $\alpha$ phase will be able to continue when the expansion stress is released by the contraction due to the precipitation of carbide in the $\alpha$ region. This fact suggests that the activation energy for the growth of lower-bainite is close to that for the carbon diffusion in the $\alpha$ region. A fairly large surface relief can be usually observed with the lower-bainitic transformation.

It is simply to say that the lower-bainitic transformation requires a cooperative atomic shear movement together with the diffusion of solute atoms, resulting in the precipitation in the matrix or the new phase $\mathrm{e}^{(2)}$.

The "Bainite-like" transformation which the authors are proposing here in oxides, points out a case in which a tetragonal to monoclinic transformation occurs isothermally in $\mathrm{ZrO}_{2}-\mathrm{Y}_{2} \mathrm{O}_{3}$ ceramics, this being similar to the eutectoid transformation, $\gamma \rightarrow \alpha+\mathrm{Fe}_{3} \mathrm{C}$, in steel. In other words, as shown in a phase diagram (Fig. 1), the bainite-

* Faculty of Science, Konan University, Okamoto, Kobe 658, Japan. like transformation occurred during isothermal holding after a rapid cooling from high temperature into the twophase region; Monoclinic + Cubic.

The "Bainite-like" transformation associates with the following phenomena: 1) A surface relief appears in the martensitic transformation from tetragonal to monoclinic, 2) this transformation; however, occurs not athermally but isothermally, and 3) this isothermal

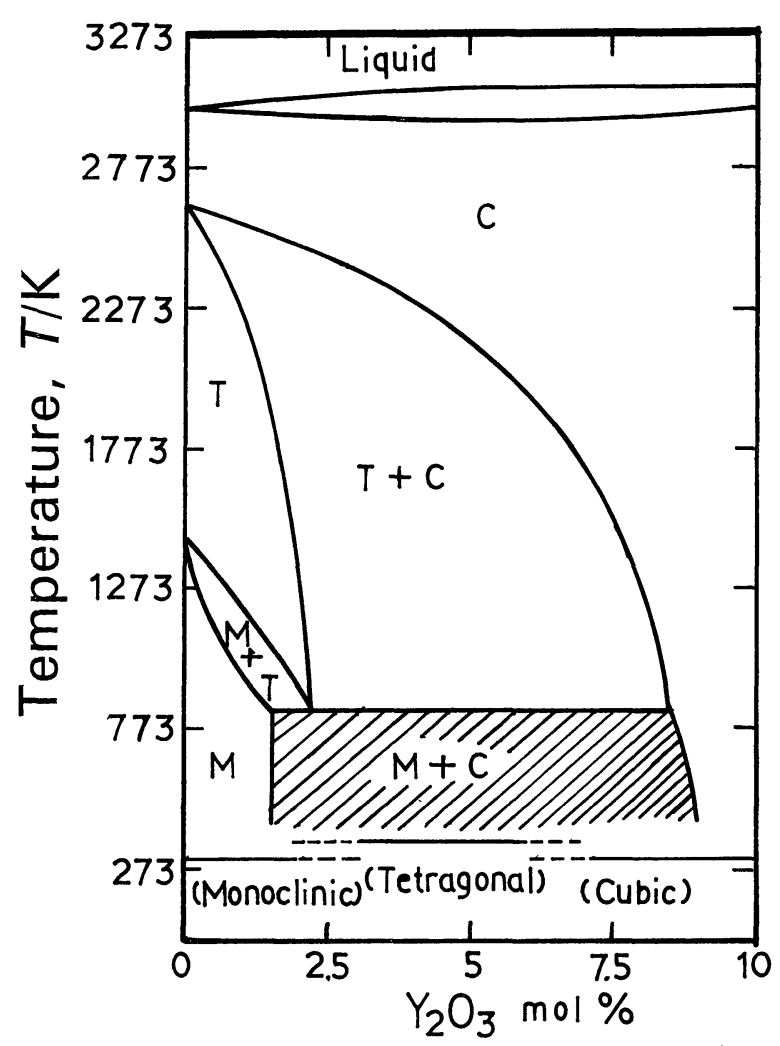

Fig. 1 Phase diagram of $\mathrm{ZrO}_{2}-\mathrm{Y}_{2} \mathrm{O}_{3}$. 
transformation, as will be shown later, is considered to be controlled by rotation or short-range diffusion of oxygen ions, this meaning that a fairly large transformation strain can be released by the short-range diffusion or rotation. An interesting experimental fact is that the progress of this isothermal transformation was clearly observed in the $\mathrm{ZrO}_{2}-\mathrm{Y}_{2} \mathrm{O}_{3}$ system, while in the $\mathrm{ZrO}_{2}-\mathrm{CeO}_{2}$ system the transformation occurred not isothermally but athermally or even as a burst type. This result may give an important problem that the existence of a large amount of oxygen vacancies introduced by replacement of $\mathrm{Zr}^{4+}$ ions by $\mathrm{Y}^{3+}$ ions in the tetragonal phase is thought to be essential for a solution of the origin of the isothermal formation. In other words, the exchange mechanism of oxygen ions and vacant lattice sites may play an important role on the isothermal propagation of the transformation.

\section{Experimental Procedure}

The raw materials were $2.2 \sim 5.0 \mathrm{~mol}^{\%} \mathrm{Y}_{2} \mathrm{O}_{3}$ and 12.0 mol $\% \mathrm{CeO}_{2}$ contained $\mathrm{ZrO}_{2}$ powders. These powders were pressed at $100 \mathrm{MPa}$, and calcined for several hours at 1673 and $1873 \mathrm{~K}$ in air. Their average grain sizes after sintering were in the range of $0.3 \sim 5.0 \mu \mathrm{m}$. X-ray diffraction, FT-IR absorption spectra, TG-DSC, bending strength and thermal expansion measurements were used to check the monoclinic amounts transformed from tetragonal phase during isothermal aging and upon cyclic thermal treatments.

\section{Results and Discussion}

\section{Isothermal propagation of the tetragonal to monoclinic transformation in $\mathrm{ZrO}_{2}-2.2 \sim 5.0$ mol $\% \mathbf{Y}_{2} \mathbf{O}_{3}$ sintered ceramics}

$\mathrm{ZrO}_{2}-\mathrm{Y}_{2} \mathrm{O}_{3}$ powder specimens were sintered for 10.8 $\mathrm{ks}$ at 1673 and $1873 \mathrm{~K}$ where about 0.5 and $2.0 \mu \mathrm{m}$ in average grain size were observed, respectively, and then isothermally held for several hours at 473 to $623 \mathrm{~K}$ in air. In (a) and (b) of Fig. 2 are shown a plot of the isothermal growth of (111) plane of monoclinic phase detected by XRD, and a TTT diagram obtained, respectively. The Ccurve behaviour in TTT diagram was also confirmed by the measurements of thermal expansion. It is to be noted that the C-curves obtained depend upon the $\mathrm{Y}_{2} \mathrm{O}_{3}$ content and grain size of the specimens. Figure 3 shows a TTT diagram in which each $\mathrm{C}$-curve is corresponding to 0.9 and $1.9 \mu \mathrm{m}$ grain sizes (in the $3.0 \mathrm{~mol}^{\circ} \mathrm{Y}_{2} \mathrm{O}_{3}$ ), and the monoclinic phase did not appear in the specimens having their grain sizes smaller than $0.5 \mu \mathrm{m}$. As shown in (a) of Fig. 4 , in the case of $1.9 \mu \mathrm{m}$ the monoclinic phase detected by XRD was observed for the shortest holding time, and other $\mathrm{C}$-curves obtained by the bending and the thermal expansion tests ${ }^{(3)}$ were observed for a little longer time in the TTT diagram. On the other hand, in the case of $0.9 \mu \mathrm{m}$ (Fig. 4(b)), the monoclinic phase was observed only by XRD and no monoclinic phase was recognized by the other tests within a $108 \mathrm{ks}$ holding
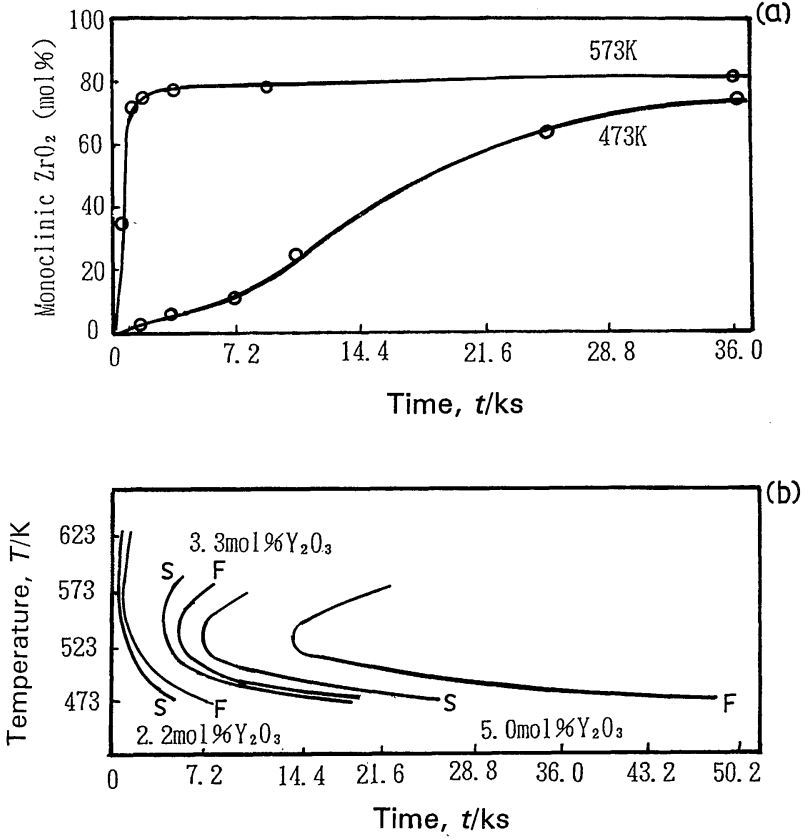

Fig. 2 Amount of monoclinic phase, (a) obtained by XRD during ageing at 473 and $573 \mathrm{~K}$ in $2.2 \mathrm{~mol} \% \mathrm{Y}_{2} \mathrm{O}_{3}$, and (b) $\mathrm{T}$ - T-T diagram resulted from isothermal ageing in $2.2,3.3$ and $5.0 \mathrm{~mol} \% \mathrm{Y}_{2} \mathrm{O}_{3}-\mathrm{ZrO}_{2}$ ceramics.

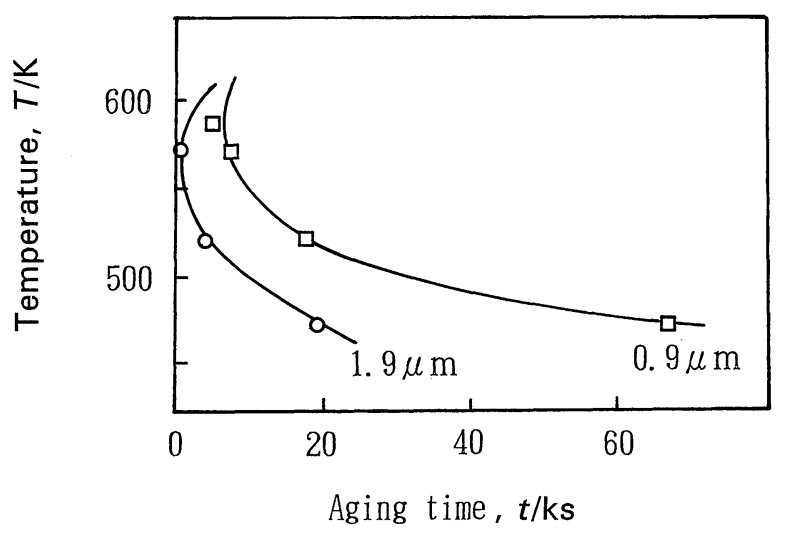

Fig. 3 T-T-T diagram obtained after ageing of $3.0 \mathrm{~mol} \% \mathrm{Y}_{2} \mathrm{O}_{3}-\mathrm{ZrO}_{2}$ ceramics determined by XRD, and the mean grain sizes were indicated in the figure.

time. This result informs us that the monoclinic phase first appeared only in the surface region and gradually proceeded into inner parts of the specimen, as has been confirmed experimentally(4). Moreover, the C-curve behaviour has been observed in air and it is well known the fact ${ }^{(5)}$ that the tetragonal to monoclinic transformation cannot occur when the experiment is carried out in vacuum. As shown in Fig. 5, the specimen of 3.0 mol $\% \mathrm{Y}_{2} \mathrm{O}_{3}$ aged at $473 \mathrm{~K}$ in air exhibits an IR sharp absorption band around $3340 \mathrm{~cm}^{-1}$ both in (a) and (b), but this absorption disappears after a reverse transformation; monoclinic to tetragonal, which was finished after the $873 \mathrm{~K}-7.2 \mathrm{ks}$ holding in air (c). This phenomenon tells us the fact that the $3340 \mathrm{~cm}^{-1}$ band caused by the stretching 


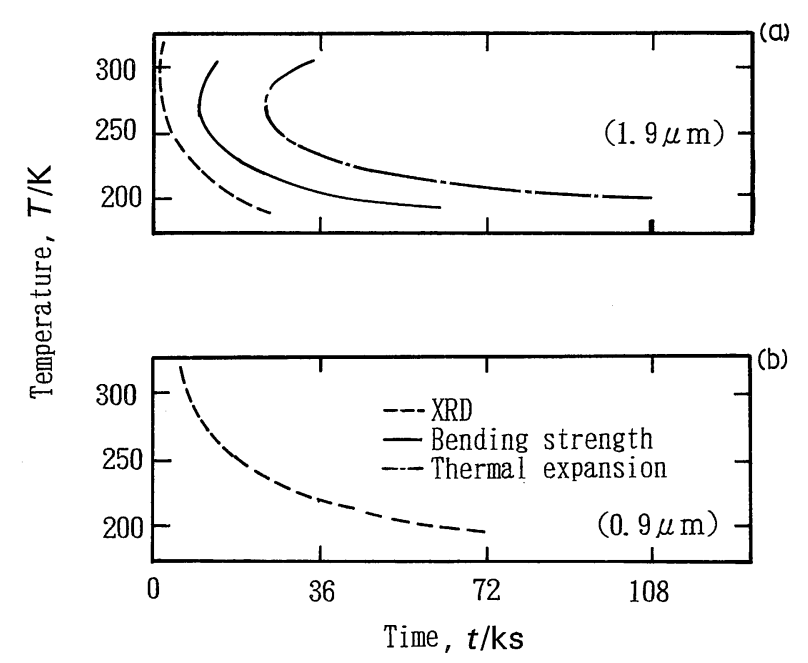

Fig. 4 T-T-T diagram obtained after ageing of $3.0 \mathrm{~mol} \% \mathrm{Y}_{2} \mathrm{O}_{3}-\mathrm{ZrO}_{2}$ ceramics, by the measurements of $\mathrm{XRD}$, bending strength and thermal expansion, (a) a grain size of $1.9 \mu \mathrm{m}$ and (b) that of $0.9 \mu \mathrm{m}$.

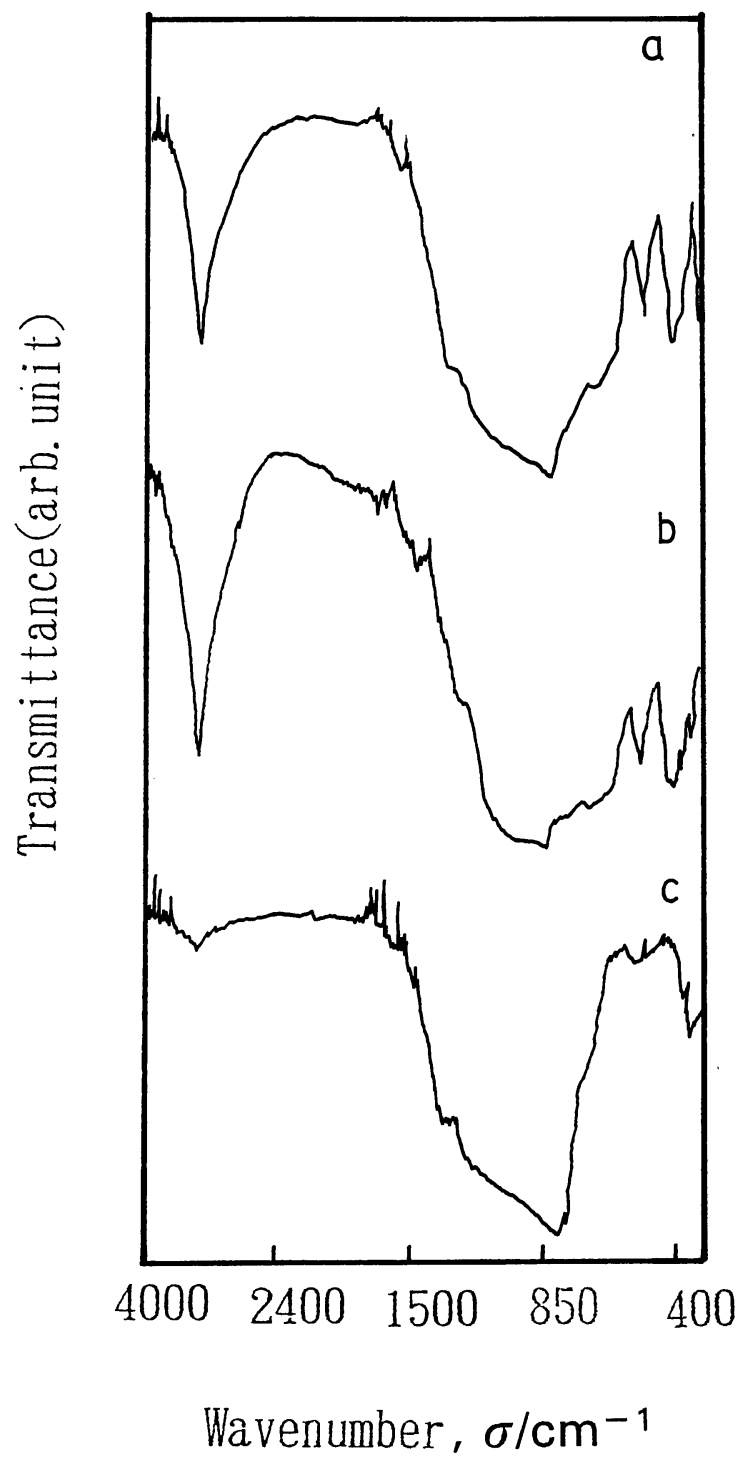

Fig. 5 FT-IR spectra of $3.0 \mathrm{~mol} \% \mathrm{Y}_{2} \mathrm{O}_{3}-\mathrm{ZrO}_{2}$ ceramics, (a) and (b) after ageing for 14.4 and $57.6 \mathrm{ks}$ at $473 \mathrm{~K}$, respectively, and (c) after heating for $7.2 \mathrm{ks}$ at $873 \mathrm{~K}$ in air. mode of the $\mathrm{O}-\mathrm{H}$ bond cannot be observed in the tetragonal phase reversely transformed from monoclinic. Therefore, the existence of the $\mathrm{O}-\mathrm{H}$ bond may have a close relation to the nucleation of monoclinic at the specimen surface. It was experimentally confirmed ${ }^{(6)}$ that the tetragonal to monoclinic transformation exhibits a gradual change to the athermal type from isothermal one according to the decrease of $\mathrm{Y}_{2} \mathrm{O}_{3}$ content of the specimen. This is because of the fact that the typical athermal nature has been observed in pure $\mathrm{ZrO}_{2}{ }^{(7)}$.

\section{Crystal structure of the monoclinic phase related} to oxygen ion defects

The crystallographic relationships between tetragonal and monoclinic phases in pure $\mathrm{ZrO}_{2}$ have been studied ${ }^{(8)}$. Here, a dynamical behaviour of oxygen ions associated with the transformation is discussed. The relative ionic positions between $\mathrm{Zr}^{4+}$ and $\mathrm{O}^{2-}$ are shown in (a) and (b) in Fig. 6, corresponding to tetragonal and monoclinic lattices, respectively. In the case of (a), the transformation into tetragonal from cubic associates with the shift of oxygen ions to the direction parallel to the $c$-axis of the cubic lattice, $\mathrm{Zr}-\mathrm{O}_{8}$ relation being maintained. This is clearly shown in Fig. 7(a) and (b), where each tetrahedron composed of four oxygen ions is mutually distorting to the $c$-axis direction; one expands and the other contracts. This transformation is thought to be

(a)

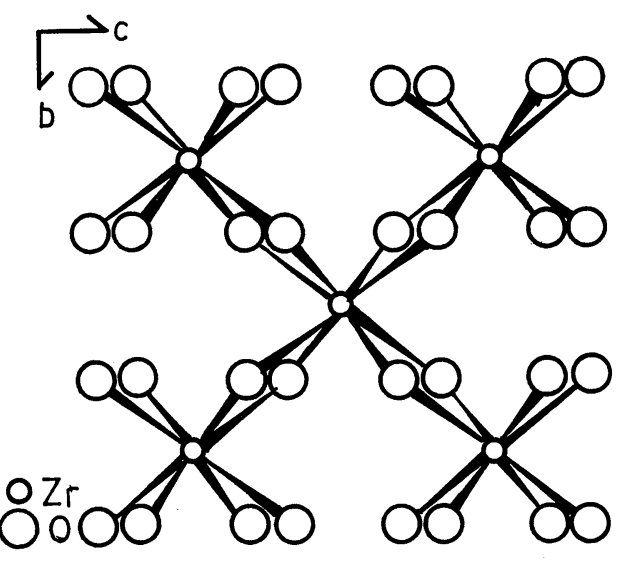

(b)

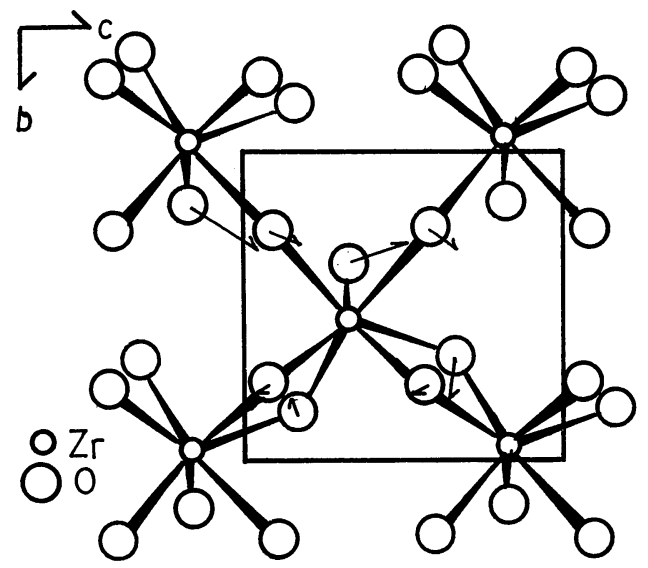

Fig. 6 Configuration of $\mathrm{Zr}-\mathrm{O}$ groups, (a) $\mathrm{Zr}-\mathrm{O}_{8}$ groups on the (100) plane in the tetragonal lattice and (b) $\mathrm{Zr}-\mathrm{O}_{7}$ groups in the monoclinic lattice after being transformed. 
(a)

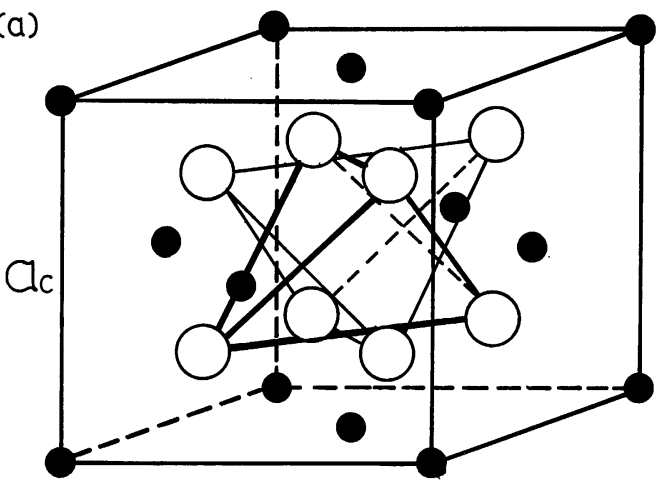

(b)

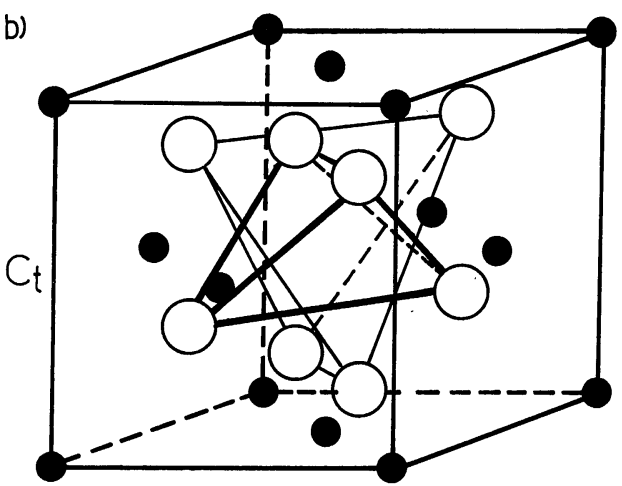

Fig. 7 Mutual configuration of two tetrahedrons, (a) consisting of 4-oxygens in the cubic lattice and (b) one in the tetragonal lattice after being shifted to $\mathrm{C}$-direction.

diffusionless and not martensitic ${ }^{(9)}$, but presumably an order-disorder type.

As already shown in Fig. 6(b), in the monoclinic lattice a complicated displacement of oxygen ions is necessary to occur, corresponding to the change in the coordination number from $\mathrm{Zr}-\mathrm{O}_{8}$ to $\mathrm{Zr}-\mathrm{O}_{7}$. So that, the authors suggest that this displacement of oxygen ions must be accompanied with the ionic shear from tetragonal to monoclinic. According to Subbarao et al. ${ }^{(10)}$, a drastic tetragonal to monoclinic transformation occurred in the temperature range, $1293 \mathrm{~K} \pm 5 \mathrm{~K}$, when the specimen was rapidly cooled from high temperature, and upon heating the reverse transformation occurred in two temperature ranges; in the former, $1203 \sim 1373 \mathrm{~K}$, an anomality in the $\mathrm{X}$-ray diffraction intensity was observed, this may being due to the ionic displacement or soft phonon modes ${ }^{(11)}$, and in the latter, $1373 \sim 1493 \mathrm{~K}$, the coexistence of two phases, tetragonal + monoclinic, was recognized in which very tiny domains of the tetragonal phase appeared in the monoclinic phase. Garvie et al. ${ }^{(12)}$ has shown that the maximum lattice vibration amplitude of oxygen ions in the $(100)_{\mathrm{m}}$ plane appears to be about $0.04 \mathrm{~nm}$ at $1339 \mathrm{~K}$. So that, small domains of the tetragonal structure can be formed in the monoclinic phase, by taking account of the Boltzmann distribution of such a lattice vibration energy.

As was described above, our specimens contain a small amount of $\mathrm{Y}_{2} \mathrm{O}_{3}$ and consequently the oxygen ion vacancies were induced by holding the ionic neutralization in the lattice;

$$
\mathrm{ZrO}_{2}+\mathrm{Y}_{2} \mathrm{O}_{3} \rightarrow 2 \mathrm{Y}_{\mathrm{Zr}}+\mathrm{V}_{\mathrm{o}}+3 \mathrm{O}_{\mathrm{o}}
$$

Here, $\mathrm{V}_{\mathrm{o}}$ is the oxygen vacancy. As the vacancy concentration increases with the increase in $\mathrm{Y}_{2} \mathrm{O}_{3}$ concentration, it is rightly expected that the tetragonal to monoclinic transformation character in the $\mathrm{ZrO}_{2}-\mathrm{Y}_{2} \mathrm{O}_{3}$ solid solution having fairly large amount of oxygen vacancies should be different from that of pure $\mathrm{ZrO}_{2}$. More recently, it has been reported ${ }^{(13)}$ that oxygen ions neighbouring their vacancies tend to occupy some interstitial sites shifted from the equilibrium lattice positions in the $\mathrm{CaF}_{2}$ type structure. As shown in Fig. 8, the shifted positions

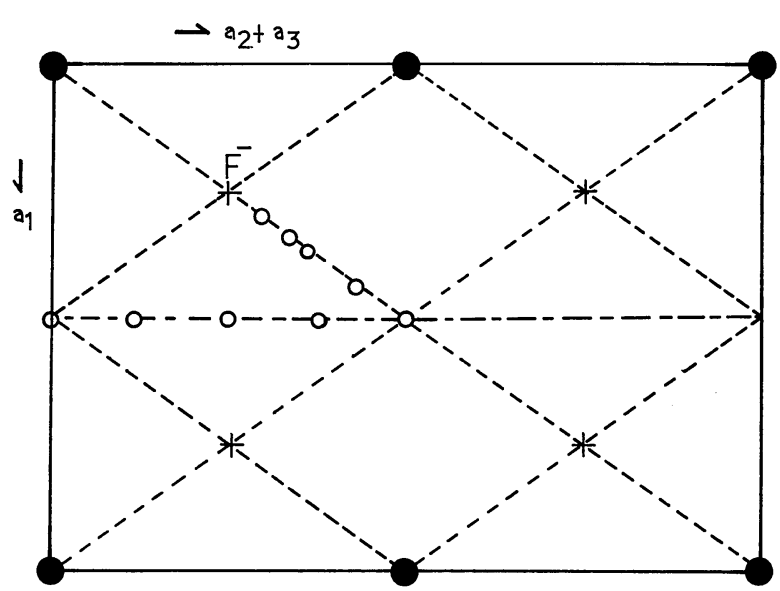

Fig. 8 Proposed interstitial sites of $\mathrm{F}^{1-}$ ions in the $\mathrm{CaF}_{2}$-type structure $^{(13)}$.

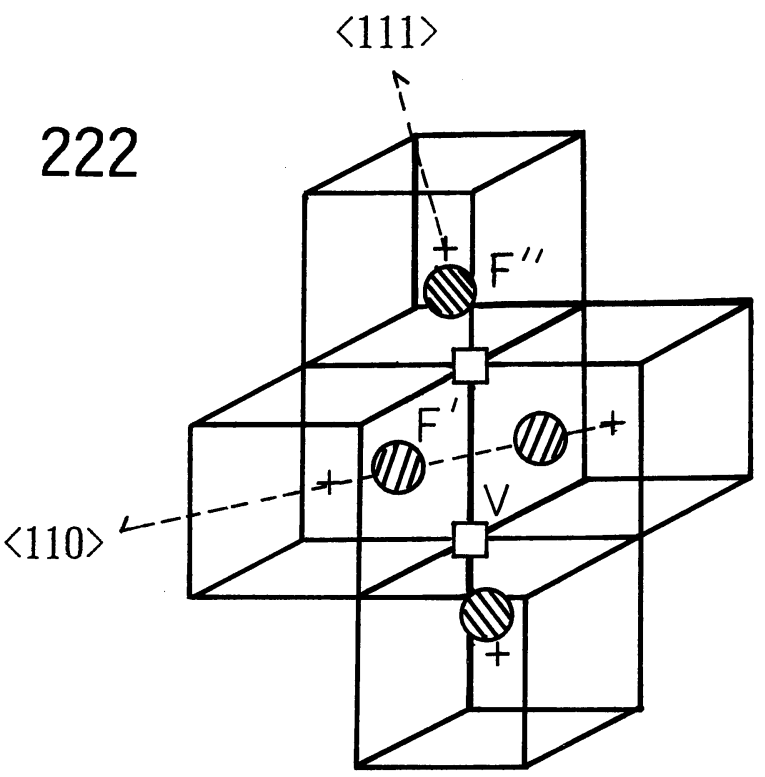

Fig. 9 The 222 cluster composed of two oxygen-ion vacancies, two interstitial $\mathrm{F}^{1-}$ ions along $\langle 111\rangle$, and two interstitial $\mathrm{F}^{1-}$ ions along $\langle 110\rangle$ directions ${ }^{(14)}$. 
are understood as the Frenkel-defect. Figure $9^{(14)}$ exhibits that the interaction between the vacancies and oxygen ions located at the Frenkel positions can produce a kind of cluster. It is probable accordingly to produce the same type of cluster or defect structure in the $\mathrm{ZrO}_{2}-\mathrm{Y}_{2} \mathrm{O}_{3}$ lattice. It is not sure practically how many of similar clusters can exist in the temperature range around $573 \mathrm{~K}$, where the isothermal transformation occurred in the tetragonal lattice.

The followings are of importance; first the shift of oxygen ions occurred in good order in the cubic-tetragonal transformation and secondly a more complicated displacement of oxygen ions (and also other cations) was required together with the martensitic shear to complete the tetragonal to monoclinic transformation. This is the basis for us to argue the "Bainite-like" for the tetragonal to monoclinic transformation in the $\mathrm{ZrO}_{2}-\mathrm{Y}_{2} \mathrm{O}_{3}$ lattice.

\section{A simple description of the isothermal propagation of tetragonal to monoclinic transformation using "Homogeneous nucleation theory".}

When the second phase begins to precipitate from the solid solution, the nucleation process occurs firstly in the matrix and subsequently the nuclei grow up by atomic diffusion.

Using a similar way, the authors try to deal with the nucleation of monoclinic lattice in the tetragonal matrix; the number of nuclei $(\dot{N})$ in the unit time and volume are given by

$$
\dot{N}=N \exp \left(-\frac{\Delta G_{n}^{*}}{R T}\right) .
$$

Here, $\Delta G_{n}^{*}$ is the activation energy for the nucleus formation having the critical size and $N$ the total number of ions. The subsequent growth of the nuclei requires the other activation energy, which is assumed to play the role of rotation or diffusion of oxygen ions in the lattice, $\Delta G_{a}$. Therefore, the growth rate of the monoclinic phase is expressed as

$$
N_{T}=K \exp \left[-\frac{\left(\Delta G_{n}^{*}+\Delta G_{a}\right)}{R T}\right]
$$

Here, $K$ is written as $K=N_{s} \cdot v \cdot N$, and $N_{s}$ is the ionic number at the surface nuclei of critical radius and $v$ the frequency number of lattice vibration $\left(10^{13} \mathrm{sec}^{-1}\right)$.

The formular (2) means that the martensitic monoclinic phase can isothermally propagate by means of both the activation energies $\left(\Delta G_{n}^{*}\right)$ for the formation of the critical nuclei and another one $\left(\Delta G_{a}\right)$ necessary to ionic diffusion. The critical size of nuclei can be estimated as follows; when a martensitic nucleus of disc shape having the radius of $r$, and the thickness $c(c \ll r)$ is formed, the total change of the Gibbs free energy is given by

$$
\Delta G_{n}=\pi r^{2} c \Delta G_{c}+2 \pi r^{2} \sigma+\pi r^{2} c\left(\frac{c}{r} A\right) .
$$

Here, $\Delta G_{c}$ is the change in the chemical free energy associ- ated with transformation per unit volume, $\sigma$ the surface energy per unit surface area, and $A$ the unit strain energy.

The critical values for the stable nucleation can be obtained by the following condition:

$$
\left(\frac{\partial \Delta G_{n}}{\partial r}\right)_{c}=\left(\frac{\partial \Delta G_{n}}{\partial c}\right)_{r}=0 .
$$

these are:

$$
\begin{aligned}
& r_{c}=\frac{16}{3} \frac{A \sigma}{\Delta G_{c}^{2}} \\
& c_{c}=\frac{-r \Delta G_{c}}{2 A} \\
& \Delta G_{n}^{*}=19 \frac{\pi A^{2} \sigma^{3}}{\Delta G_{c}^{4}} .
\end{aligned}
$$

Since the values $\sigma$ and $A$ are assumed to be constant against the temperature change, then

$$
\Delta G_{c}=\Delta H_{c}-T \Delta S_{c} \cong \Delta S_{c}^{e} \cdot \Delta T
$$

can be given. Here, $\Delta S_{c}^{e}$ is the entropy change at the equilibrium temperature, $T_{0}\left(T_{0} \cong 1 / 2\left(M_{\mathrm{s}}+A_{\mathrm{s}}\right)\right)$ and $\Delta T$ is expressed as $\Delta T=T_{0}-T$.

Assuming roughly the value of $\Delta S_{c}^{e}$ is constant against the temperature change, and $\Delta G_{c}$ is proportional to $\Delta T$, the formular $\Delta G_{n}^{*}$ in (5) can be expressed as

$$
\Delta G_{n}^{*}=\frac{\Delta G_{n}^{0}}{(\Delta T)^{4}} .
$$

This formula shows that the critical value $\Delta G_{n}^{*}$ is inversely proportional to $(\Delta T)^{4}$, that is super cooling. The formula described in (2) means that with decreasing temperature, the value of $\Delta G_{n}^{*}$ can be remarkably decreased by the term $(\Delta T)^{4}$, while that of $\Delta G_{a}$ is almost constant, and consequently the C-type behaviour of $N_{T}$ can be obtained (see Fig. 10). In other words, there exists a maximum growth rate in the TTT diagram and this is controlled by the diffusion of oxygen ions.

Generally speaking, the typical athermal martensitic transformation can propagate very rapidly just after the nucleation (meaning $\Delta G_{a}=0$ ), where the isothermal growth cannot be observed. In practice, the martensitic nucleation can occur not homogeneously but heterogeneously, meaning that the values of $\Delta G_{n}^{*}, r_{c}$ and $c_{c}$ should become smaller by the existence of surface defects.

As mentioned already, the tetragonal to monoclinic transformation was experimentally confirmed to occur by the triggering role of $\mathrm{H}_{2} \mathrm{O}$ existing on the specimen surface, so that the real mechanism to transform the tetragonal lattice may be more complicated. The triggering role of surface $\mathrm{H}_{2} \mathrm{O}$ upon the tetragonal to monoclinic transformation is thought to be a surface reaction:

$$
-\mathrm{Zr}-\mathrm{O}-\mathrm{Zr}-+\mathrm{H}_{2} \mathrm{O} \rightarrow 2(-\mathrm{Zr}-\mathrm{O}-\mathrm{H})^{(15)} \text {. }
$$

Using the values of $T_{0}$ and $T_{\mathrm{N}}$ (the nose temperature) in the $\mathrm{ZrO}_{2}-5.0 \mathrm{~mol} \% \mathrm{Y}_{2} \mathrm{O}_{3}$ sintered specimen and 96.2 


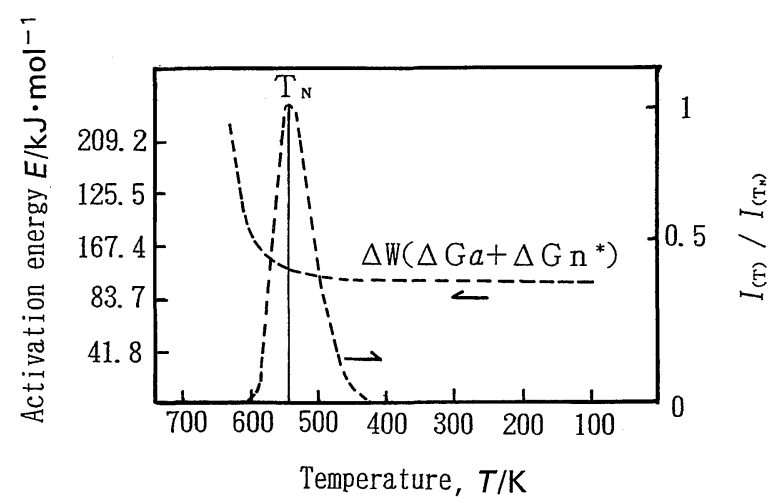

Fig. 10 The change in the activation energy, $\Delta W$, and $I_{(T)} / I_{\left(T_{N}\right)}$ values against temperature $\left(5.0 \mathrm{~mol} \% \mathrm{Y}_{2} \mathrm{O}_{3}-\mathrm{ZrO}_{2}\right)$.

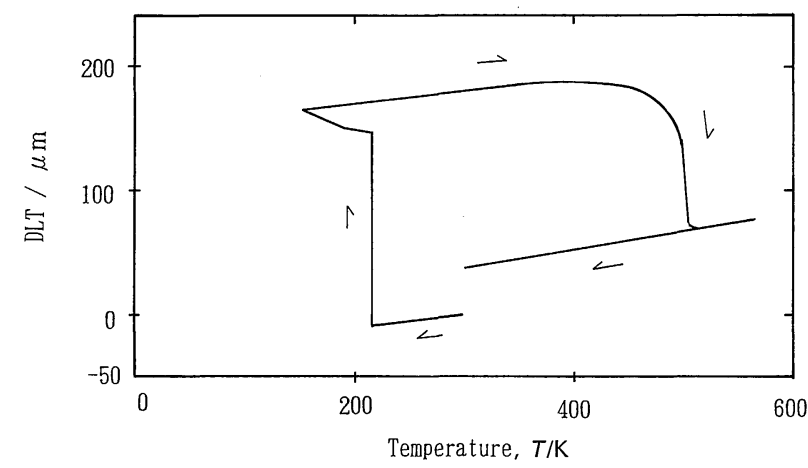

Fig. 11 Thermal expansion behaviour upon cyclic treatment in 12.0 $\mathrm{mol} \% \mathrm{CeO}_{2}-\mathrm{ZrO}_{2}$ ceramics.

$\mathrm{kJ} / \mathrm{mol}$ for the value of $\Delta G_{a}$, Fig. 10 can be obtained, where the changes in $\Delta W \quad\left(=\Delta G_{n}^{*}+\Delta G_{a}\right)$ and in the nucleation ratio, $I_{(T)} / I_{\left(T_{\mathrm{N}}\right)}$, which equals $\exp [-\Delta W / R T] / \exp \left[-\Delta W / R T_{\mathrm{N}}\right]$, are plotted against temperature change.

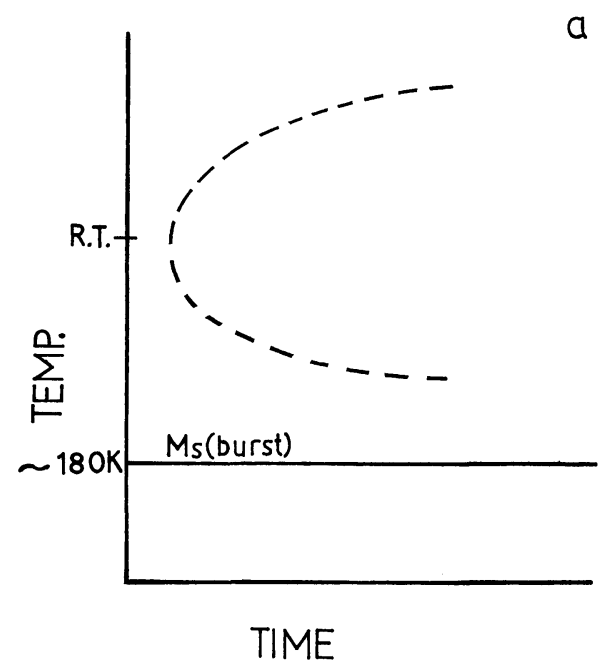

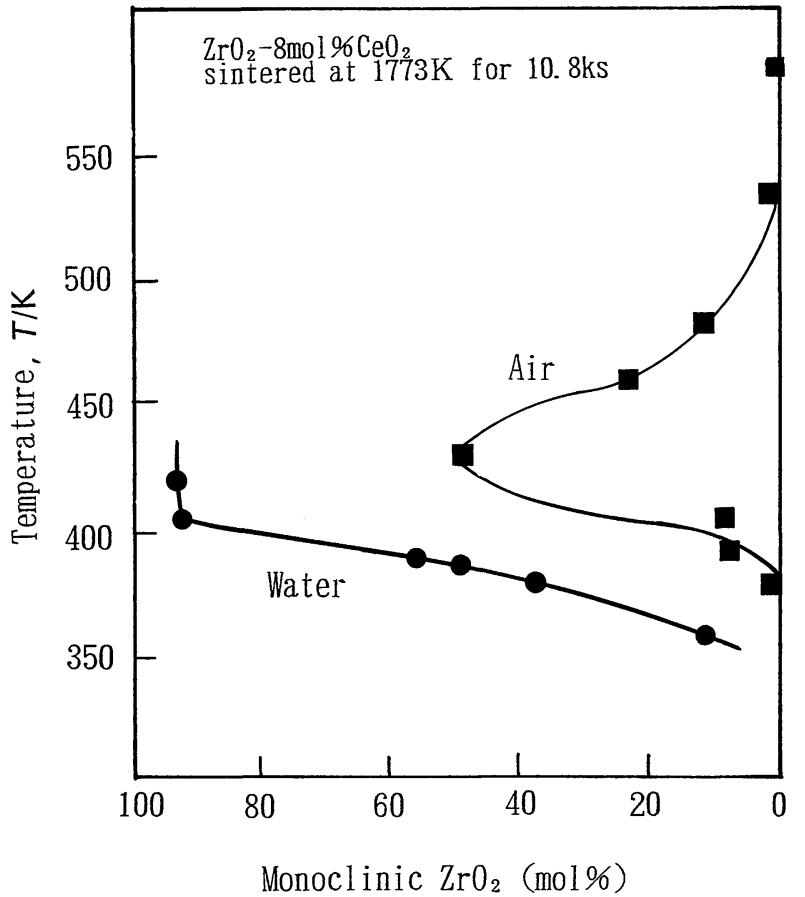

Fig. 12 Amount of monoclinic formed on the surface by isothermal annealing in air and water ${ }^{(16)}\left(8 \mathrm{~mol} \% \mathrm{CeO}_{2}-\mathrm{ZrO}_{2}\right)$.

\section{Characteristics of the tetragonal to monoclinic transformation in $\mathrm{ZrO}_{2}-\mathrm{CeO}_{2}$ ceramics}

It is so far discussed about the isothermal character of the tetragonal to monoclinic transformation which appeared in $\mathrm{ZrO}_{2}-\mathrm{Y}_{2} \mathrm{O}_{3}$ system, and as a result, the followings are of very importance: (i) The addition of $\mathrm{Y}_{2} \mathrm{O}_{3}$ to $\mathrm{ZrO}_{2}$ generated many oxygen ion vacancies in the tetragonal lattice to hold the ionic neutralization, (ii) these vacancies existing as the Frenkel-type defect made the diffusion of oxygen ions much easier, and resulted in a role to arrest the athermal propagation of tetragonal to

Fig. 13 Assumptive T-T-T diagram, (a) in the case of $12.0 \mathrm{~mol} \% \mathrm{CeO}_{2}-\mathrm{ZrO}_{2}$ and (b) of $3.0 \mathrm{~mol} \% \mathrm{Y}_{2} \mathrm{O}_{3}-\mathrm{ZrO}_{2}$ ceramics. 
monoclinic transformation and (iii) the whole character of this transformation behaved like "Bainitic", because the transformation can be controlled by the oxygen ion diffusion.

On the other hand, in the case of $\mathrm{CeO}_{2}$ addition the socalled chemical vacancies are not necessary to exist under the thermal equilibrium state assuming the existence of only $\mathrm{Ce}^{4+}$ ions, and the athermal behaviour of tetragonal to monoclinic transformation can be naturally expected. This is the case in Fig. 11, in which the thermal expansion associating with the tetragonal $\rightleftharpoons$ monoclinic transformation cycle exhibits clearly athermal, even more burstnature in the $\mathrm{ZrO}_{2}-12 \mathrm{~mol} \% \mathrm{CeO}_{2}$ sintered specimen. However, an experimental result ${ }^{(16)}$ of $\mathrm{ZrO}_{2}-8.0$ $\mathrm{mol} \% \mathrm{CeO}_{2}$ in air and water exhibited an evidence of isothermal propagation of the tetragonal to monoclinic transformation as well as the case of $\mathrm{ZrO}_{2}-\mathrm{Y}_{2} \mathrm{O}_{3}$, although the beginning time of the monoclinic shifted to longer time compared with the case of $\mathrm{Y}_{2} \mathrm{O}_{3}$ (Fig. 12).

Unfortunately, this isothermal nature has not been observed in the $12 \mathrm{~mol} \% \mathrm{CeO}_{2}$ specimen, so that the retained problem is to check in detail. If it is assumed that the isothermal transformation appears together with the athermal one in the case of $12 \mathrm{~mol} \% \mathrm{CeO}_{2}$, as described in Fig. 13(a), a similar phenomenon to the appearance of lower bainite in steels can be realized. Moreover, if we found out the athermal martensite at subzero temperatures in the case of $\mathrm{ZrO}_{2}-\mathrm{Y}_{2} \mathrm{O}_{3}$, the same situation will be expected (Fig. 13(b)). So far it is not the case. The other important thing is to re-examine the crystal stucture of monoclinic lattice, especially the position of oxygen ions bonded to $\mathrm{Zr}$ ions $\left(\mathrm{Zr}-\mathrm{O}_{7}\right)$, athermally transformed from tetragonal lattice in the $\mathrm{ZrO}_{2}-\mathrm{CeO}_{2}$ system and to compare it with that formed isothermally in the $\mathrm{ZrO}_{2}-\mathrm{Y}_{2} \mathrm{O}_{3}$ system. Further experiments will be needed to solve these interesting problems.

\section{REFERENCES}

(1) Z. Nishiyama: Martensitic transformation, Application Series, Maruzen, Tokyo, (1974), p. 63.

(2) H. I. Aaronson and G. W. Lorimer: Scripta Metall., 6 (1972), 1091.

(3) T. Shigematsu and N. Nakanishi: JJAP, Series 2 (1989), 159.

(4) N. Nakanishi, T. Shigematsu, T. Sugimura and H. Okinaka: J. Jap. Soc. Powder and Powder Met., 33 (1986), 356.

(5) K. Kuroda, H. Saka, S. Iio, M. Watanabe and T. Imura: Proc. ICOMAT-86, Japan Inst. Metals, (1986), p. 1161.

(6) N. Nakanishi, T. Shigematsu, T. Sugimura and H. Okinaka: Zirconia Ceramics, Uchida Rokakuho, Tokyo, (1986), p. 71.

(7) G. M. Wolten: J. Amer. Ceram. Soc., 46 (1963), 418.

(8) M. Hayakawa and M. Oka: Mater. Sci. Foram, 56-58 (1990), p. 383.

(9) T. Sakuma, H. Eda and H. Suto: Proc. ICOMAT-86, Japan Inst. Metals, (1986), p. 1149.

(10) E. C. Subbarao, H. S. Maiti and K. K. Srivastava: Phys. Status Solidi, a21 (1974), 9.

(11) C. Grain and R. Garvie: U. S. Bur. Mines Rept. Invest. R 16619 (1963), p. 19.

(12) S. Burke and R. Garvie: J Mater. Sci. Lett., 12 (1977), 1487.

(13) K. Koto, H. Schulz and R. A. Huggins: Solid State Ionics, vol. 1 (1980), 355.

(14) A. K. Cheetham, B. E. F. Fender: J. Phys. C (Solid State Phys.), 4 (1971), 3107.

(15) T. Shigematsu, Y. Nakao and N. Nakanishi: Proc. MRS-88, (1989), p. 549

(16) T. Sato and M. Shimada: Amer. Ceram Soc. Bull., 64 (1985), 1382 . 